\title{
Study ON RUlE CuRVE DEVElOPMENT FOR HydRO Electric POWER (HEP) DAM Operation. CASE STUDY: MURUM HEP DAM
}

\author{
Gregory Titus $^{1}$ and Frederik Josep Putuhena ${ }^{2}$ \\ ${ }^{1}$ R\&D Dept, Sarawak Energy Berhad, 93050 Kuching, Sarawak, Malaysia \\ ${ }^{2}$ Civil Engineering Department, Faculty of Engineering Pancasila University, Indonesia \\ Date received: 24/07/2016, Date accepted: 09/09/2016 \\ Corresponding author's email: gregtitus@ sarawakenergy.com.my
}

\begin{abstract}
An operation rule curve of a dam provides specific on the target elevation of the reservoir. This can vary throughout the year. This is an indication to the reservoir operator of activities to conduct for various situations involving reservoir and the hydrologic conditions. This rule curve shall apply to Murum dam solely for power generation purpose. The decisions on when and how much to release will impact the ability to pass a flood as well as hydropower capacity. The main objective of this research is to select the most suitable method and to develop the operation rule curves for Murum dam primarily for hydropower generation. A trial-and-error method has been selected for this study. Reservoir operation modeling and simulation have been commenced using historical rainfall data, after runoff was generated by rainfall runoff modellings. Three (3) simulations are conducted for developing the operation rule curves. They are rule curve according to Sarawak Energy Berhad's requirement, ideal rule curve and mean rule curve. All three sets of rule curves are successfully developed using turbine discharges of the dam as the parameters and to achieve the target firm energy generation of $635 \mathrm{MW}$.
\end{abstract}

Keywords: Operation Rule Curve, Reservoir, Murum Dam, Hydropower.

\subsection{INTRODUCTION}

A rule curve consists of a set of storage levels or water levels for every time of the year, indicating to the reservoir operator of things should be done for various combinations of reservoir storage and (expected) hydrologic conditions [1]. From this statement, a reservoir has not one but a few sets of operation rules known as rule curves. A rule curve is constituted by a standard operation rule which uses the full supply level (FSL) to have the subdivision for the reservoir storage.

The rule curve concept has been used as a criterion in dam reservoir operation. It is recognized that focuses are on most reservoir operations and thus there is a requirement to come up with better set of rule curves with some agreements on the typical objectives. Among the objectives required are the storage conservation to ensure reliability of the water flow, implementation of empty space in the reservoir for flood control, having possibility of high water level and high sustainable flow for maximum energy generation and etc. [1].

\section{Background}

Murum Hydro Electric Project (HEP) is situated about $200 \mathrm{~km}$ from Bintulu in Sarawak, Malaysia. The dam site is located on the Murum River which is at the head source of Rajang river basin. After Batang Ai HEP in the 1980s, this is the second Hydro Electric Project 
(HEP) to be developed by Sarawak Energy Berhad (SEB). Figure 1 shows the location for Murum dam encircled in red. This dam is a roller-compacted concrete dam (RCC) with a height of $141 \mathrm{~m}$ and a catchment area of about $2750 \mathrm{~km} 2$. The size of the reservoir is 245 $\mathrm{km}^{2}$. The dam uses the power of the water flowing through turbines (four sets of $236 \mathrm{MW}$ Francis turbine generating units) to generate $944 \mathrm{MW}$ of electricity.

The Murum River is situated within the upstream of Rajang Basin which has a total catchment area of $51,153 \mathrm{~km}^{2}$. The mean annual rainfall at Rajang Basin is ranging from $2450 \mathrm{~mm}$ to $3500 \mathrm{~mm}$ [2], [3]. Climate condition is relatively similar throughout Sarawak state. The air temperature and relative humidity are usually high with little variations. It has long term average annual rainfall of $3756 \mathrm{~mm}$ while the long term average annual evaporation is $1184 \mathrm{~mm} \mathrm{[2],} \mathrm{[3].}$

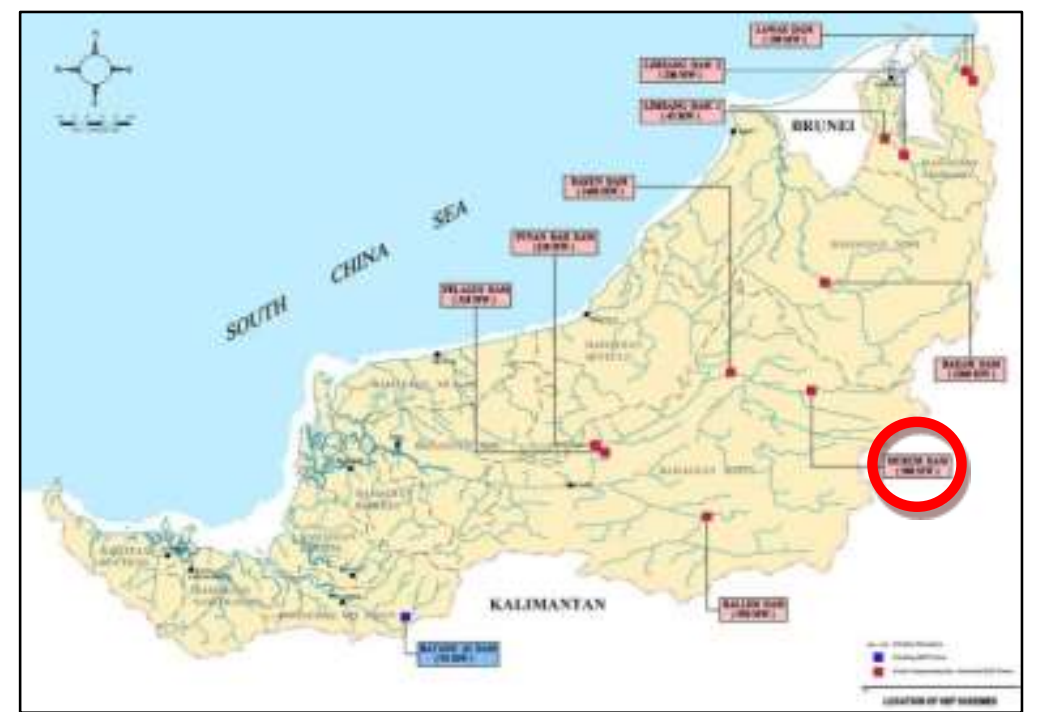

Figure 1: Location of Murum Dam (in red circle)

\section{Objectives and Scope of Work}

There are uncertainties of inflow to the reservoir and improper reservoir operation are related to the risks, which incur cost of environmental damages and cost to the community living downstream or nearby due to the loss of a water supply and transportation.

The rule curve development is important in hydropower particularly on the reservoir operations like Murum dam, in which the setup of rule curves define the reservoir operation, for optimizing power generation. At the same time, the development process of rule curve must ensure the sustainability of the environment by drawing up minimum required flow or residual flow. From this, the risk which results in the two costs mentioned above can thus be minimised.

It is essential to have a thorough study on the hydraulic characteristics and dam reservoir operation to produce the appropriate rule curve for Murum dam as the main objective of this study. The scope of the works and information required for the objective of the study are as follow: 
- Review the various methods to develop and produce the rule curves for Murum reservoir operation.

- Study the characteristics of the dam reservoir and its river such as the inflow, outflow and water level especially in Murum River and also Rajang Basin based on the data provided by the Department of Irrigation and Drainage (DID) and Sarawak Energy Berhad (SEB).

- Apply the appropriate method to produce the rule curves for reservoir operation at Murum dam which includes consideration for the environmental flow and water supply in line with Sarawak Integrated Water Resources Management.

\subsection{LITERATURE REVIEW}

\section{Methods in Developing Rule Curve}

The reservoir planning and operation shall be set up with appropriate set of rule curves and at the same time, taking into consideration the environment sustainability through minimum required flow or residual flow. All these considerations also take into account the requirements by Sarawak Integrated Water Resources Management especially for water supply to the populace. In developing the rule curves, there are various techniques and methods in connection to the hydrologic characteristics as well as the reservoir purposes such as follow;

- The trial and error method which touches on mass curve methods:-

- Parameterization-optimization-simulation approach which involves simulations for an infinite reservoir, finite reservoir and fixed reservoir size:-

- Comparing decision trees with neural decision trees and fuzzy decision trees:-

- Dynamic programming (DP):-

- Stochastic dynamic programming (SDP):-

- DP with principle progressive optimality (DP-PPO):-

- Genetic algorithm (GA):- and

- Application of Microsoft Excel Solver.

From these methods, trial and error method shall be used for this study. The development of rule curve planning for management of reservoir commences with this method. This method of using trial and error approach is straight forward, easy to understand and can be used for simple and complicated reservoir systems.

\subsection{METHODOLOGY}

Hydrologic and hydraulic analyses are needed to perform the reservoir operation study and development of operation rule curve. Information and works to be done for this study are as follow:

a) Generated series of net inflow to the reservoir based on rainfall runoff:-

b) Series of river outflow from the reservoir:-

c) Release of water between the Murum dam and the power plant tailrace:-

d) Spillage from dam spillway:-

e) Required demand for firm and/or maximum power generation:-

f) Area-storage relationship:- and

g) Power output of Murum hydro power plant. 


\section{Aquarius Forecast}

Aquarius Forecast is the modelling software used for advanced environmental modelling, which delivers high accuracy and speed with real time series inputs and outputs. The input rainfall data are automatically converted to the required runoff model at required time step [4]. It is used to develop the rainfall runoff relationship based on Australian Water Balance Model (AWBM) in producing the inflow series for this study. AWBM is a catchment-based water balance model that calculates runoff from rainfall at daily or hourly increments [6]. The AWBM model adopts the usage of three (3) surface soils and ground water storage to process the catchment runoff. Each soil water storage is responsible for each part of the catchment with different runoff rate. The runoff model has two outputs which are direct runoff whereby the soil storages are exceeded and a base flow that has a proportional rate to the depth of water in the ground water.

A rainfall runoff model has been developed and the inflow series range from 1984 till 2014. SEB's Hydro Department has the inflow series from September 2013 till December 2014. The rainfall runoff series are compared and calibrated using SEB's existing Murum HEP inflow series. Calibration is done through the adjustment of the shape of runoff model series to follow the shape of the existing inflow series on the same period of time as indicated in Figure 2. After the calibration works, the full inflow series (in blue) are then generated from 1984 to 2014 together with existing inflow series (in red) as shown in Figure 3. These inflow series are applied in the stream flow sequential routing method using trial and error procedures.

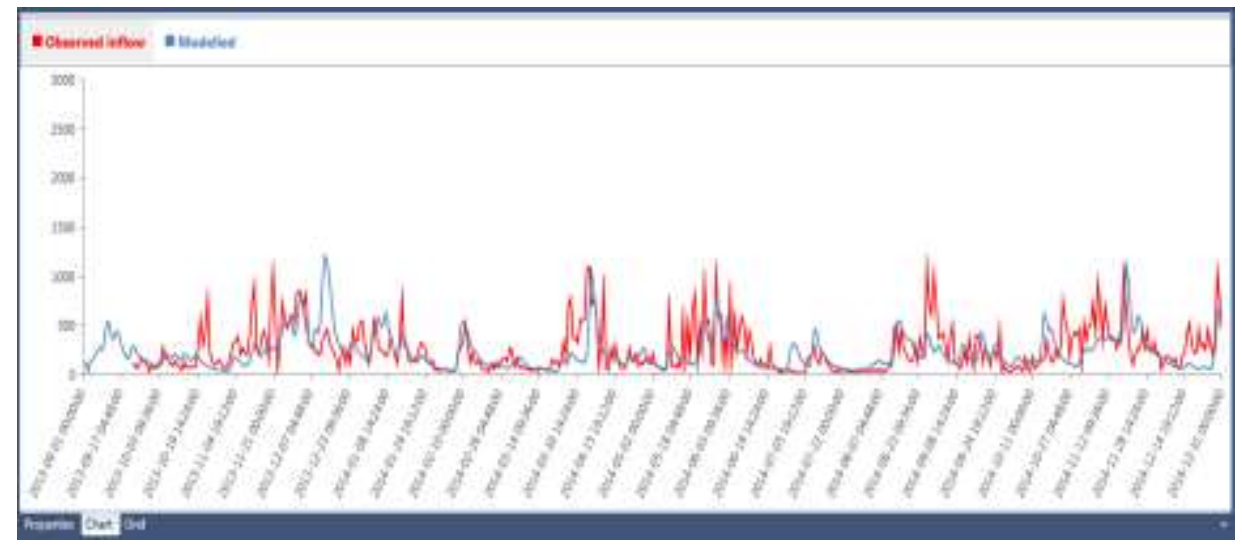

Figure 2: Calibration Using Inflow Series from September 2013 to December 2014

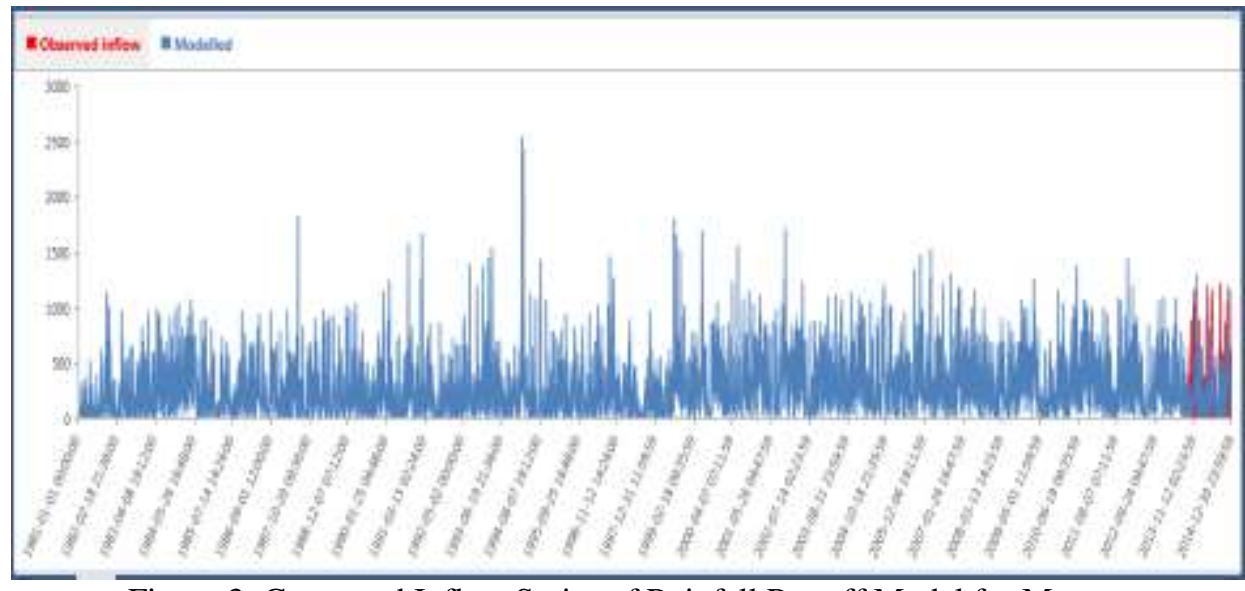

Figure 3: Generated Inflow Series of Rainfall Runoff Model for Murum 


\section{Trial \& Error Method}

Using trial and error method involves the application of graphical understanding of various hydrological aspects and the reservoir function. This is to combine all parameters in such ways that the understanding must prevail even with using the most advanced and complicated methods.

Various considerations are taken into account for using this method. One of them is single purpose; for flood control, energy generation (firm or total maximum generation), water rationing and level control or environmental flow. As for multi-purpose operations, there is a need to create a few zones so as to satisfy the requirements for joint operation of the reservoir. Another simulation which considers the losses through the adaptation of water balance equation is also conducted for this purpose. It is essential to incorporate the losses to compute the appropriate reservoir capacity for various conditions like dry season and wet season [5].

The mass balance equation states for a selected time interval the volume of storage at the end of the interval $(\mathrm{Ve})$ is equal to the storage at the beginning of the interval $(\mathrm{Vb})$ plus the inflow $(\mathrm{Q})$ and minus the outflow (O) [1]. The equation is as follow:

$\mathrm{Ve}=\mathrm{Vb}+\mathrm{Q}-\mathrm{O}$

The outflow can be further differentiated into useful outflow satisfying a particular draft (D), spilling (Sp) and losses (Ls) [1]. Specification for this equation is for an exceptional period, $t$, if the time $t$ is the starting time of the period then the equation is revised as;

$V^{t+1}=V^{t}+Q^{t}-D^{t}-S p^{t}-L s^{t}$

\section{Sequential Stream Flow Routing Method}

The sequential streamflow routing method is based on the continuity equation and accounts for changes in streamflow due to storage regulation. This method is used for evaluating the energy output of storage projects or projects that are part of a system which includes one or more storage projects [7].

According to reports by the U.S Army Corps of Engineers, the hydropower projects done by them are multipurpose hydropower plants that are having functions like flood control, water supply and navigation. Modelling of the reservoir operation requires criteria for each function in order to develop the operation rule to achieve the required goals. Then, the reservoir undergoes regulation or optimization to get the best possible hydropower benefit. This can be done in trial and error method.

From the above methodology, the setting of the operating rule curve shall be as follow:

a) Rule curve to meet SEB's requirement of firm generating capacity of $635 \mathrm{MW}$ and reservoir operating level between $515.0 \mathrm{~m}$ and $540.0 \mathrm{~m}$.

b) Proposed rule curve based on regulated dam outflow.

c) Ideal rule curve which is also in accordance to controlled dam outflow. 
All reservoir rule curves produce graphical results of mean inflow series, minimum and average operating level. The minimum operating level refers to the lowest reservoir level of the simulated rule curve for each month (January to December) throughout the period of year 1984 to 2014. Same scenario applies for the average operating level too.

\subsection{RESULTS, ANALYSES AND DISCUSSIONS}

\section{Rule Curve (SEB)}

This operating rule curve is based on SEB's requirement that the reservoir water level must be within $515.0 \mathrm{~m}$ to $540.0 \mathrm{~m}$ range. SEB has allowed provision for $\mathrm{n}-1$ operation; that is during all four (4) turbines operating, it is still acceptable for the hydro plant to continue running with three (3) turbines if one experiences breakdown or under maintenance. For this requirement, the turbine discharges are adopted as the parameter for the simulation. Discharge of $344.0 \mathrm{~m} 3 / \mathrm{sec}$ is representing the operation of four (4) turbines at reservoir level greater than $540.0 \mathrm{~m}$ and $260.0 \mathrm{~m} 3 / \mathrm{sec}$ is for level greater than $515.0 \mathrm{~m}$. The main purpose is to ensure sufficient water to provide power to SCORE customers by generating firm supply of $635 \mathrm{MW}$ which is ninety five percent $(95 \%)$ of flow exceeded all the time.

This simulation is done for years 1984 to 2014. For this case, the overall result for rule curve is shown in Figure 4. This analysis indicates no significant drop in the water level of the dam's reservoir. In fact, the regulated operating level is very constant throughout the years. The month of October 1991 recorded the lowest level at $513.20 \mathrm{~m}$ which is below the minimum operating level of $515.0 \mathrm{~m}$ but bounces back to $515.03 \mathrm{~m}$ the following month. Firm generating capacity computed is expected at $637.46 \mathrm{MW}$ which is close to SEB's requirement. The developed operating rule curve is illustrated in Figure 5.

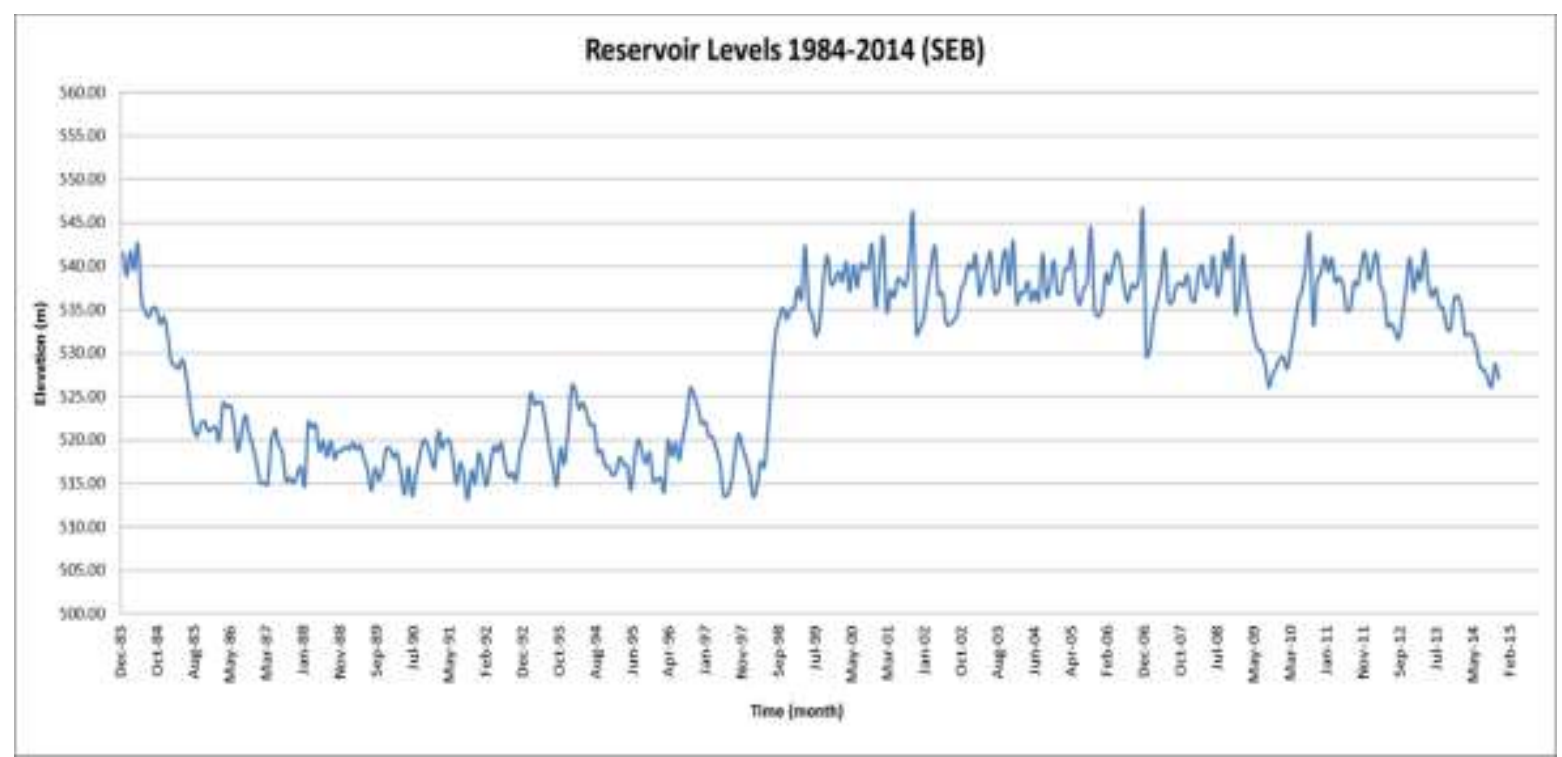

Figure 4: Murum HEP Overall Operating Rule Curve (SEB) 


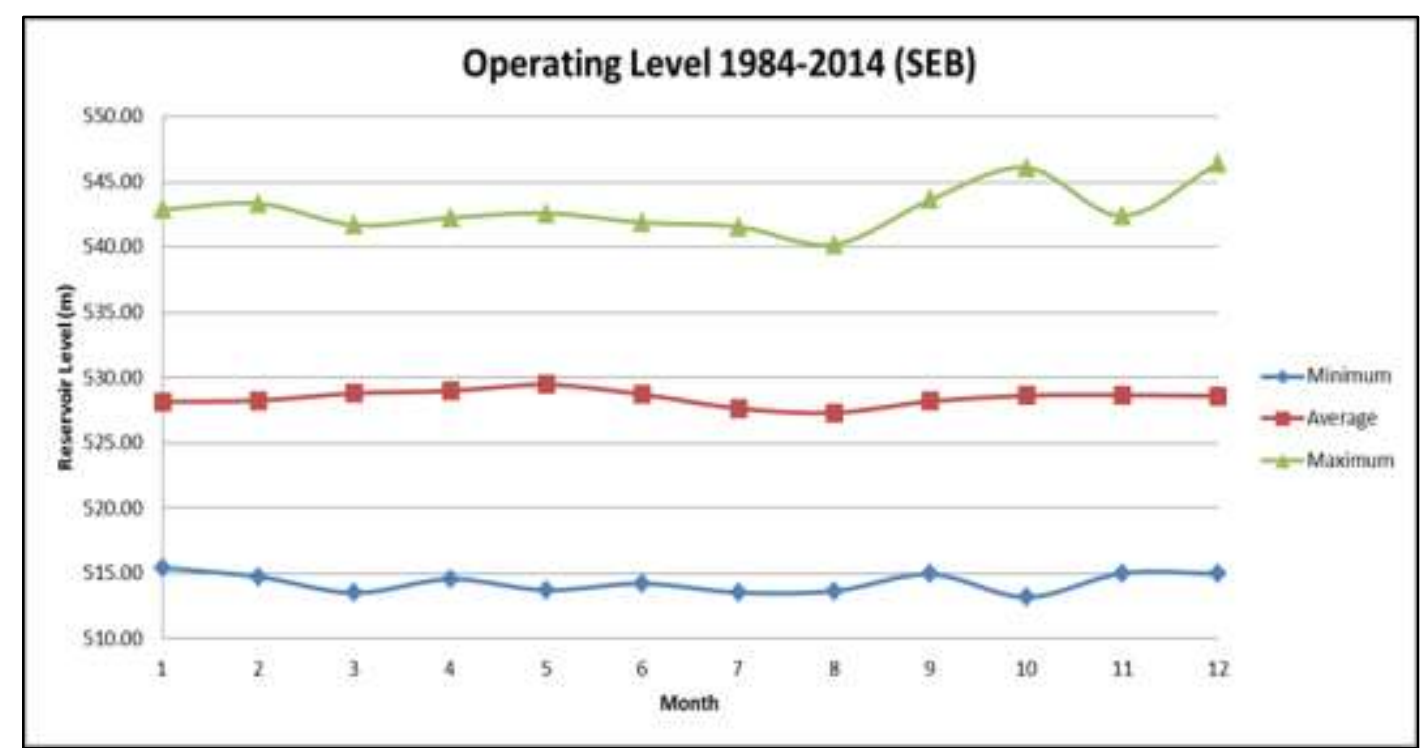

Figure 5: Operating Rule Curve (SEB)

\section{Ideal Rule Curve for Murum HEP}

Just like in previous section, the turbine discharges are adopted as the parameters in this model. For this proposal, the total outflow is regulated to achieve the most idealistic curve for this reservoir. The regulated ideal outflow is explained in Figure 6 which states the required total outflow to produce the ideal rule curve.

From the analysis, the month of June 1998 recorded the lowest level at $517.75 \mathrm{~m}$; above the minimum operating level of $515.0 \mathrm{~m}$. This curve produces firm generation of $588.41 \mathrm{MW}$. Hence, the operating rule curve is illustrated in Figure 7.

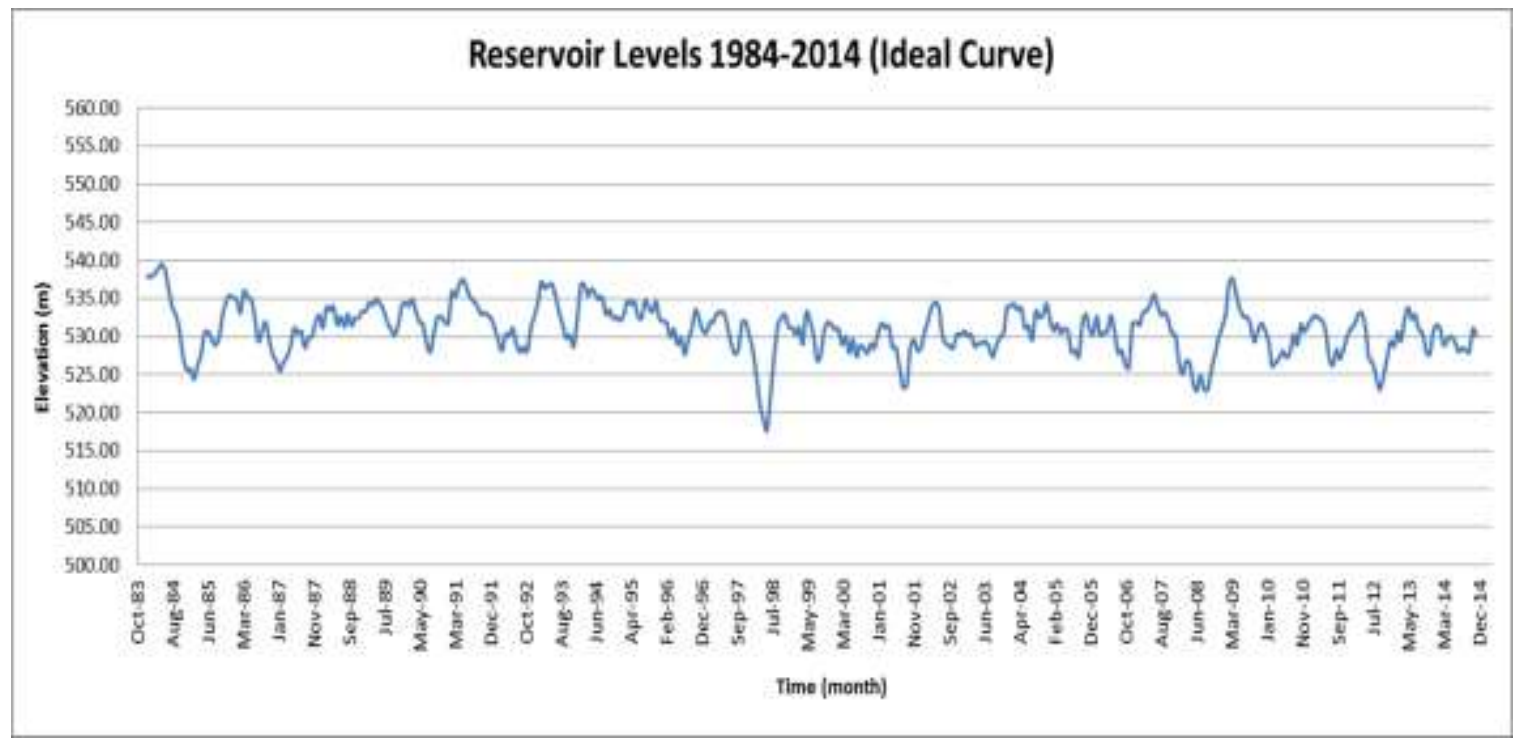

Figure 6: Murum HEP Overall Ideal Rule Curve 


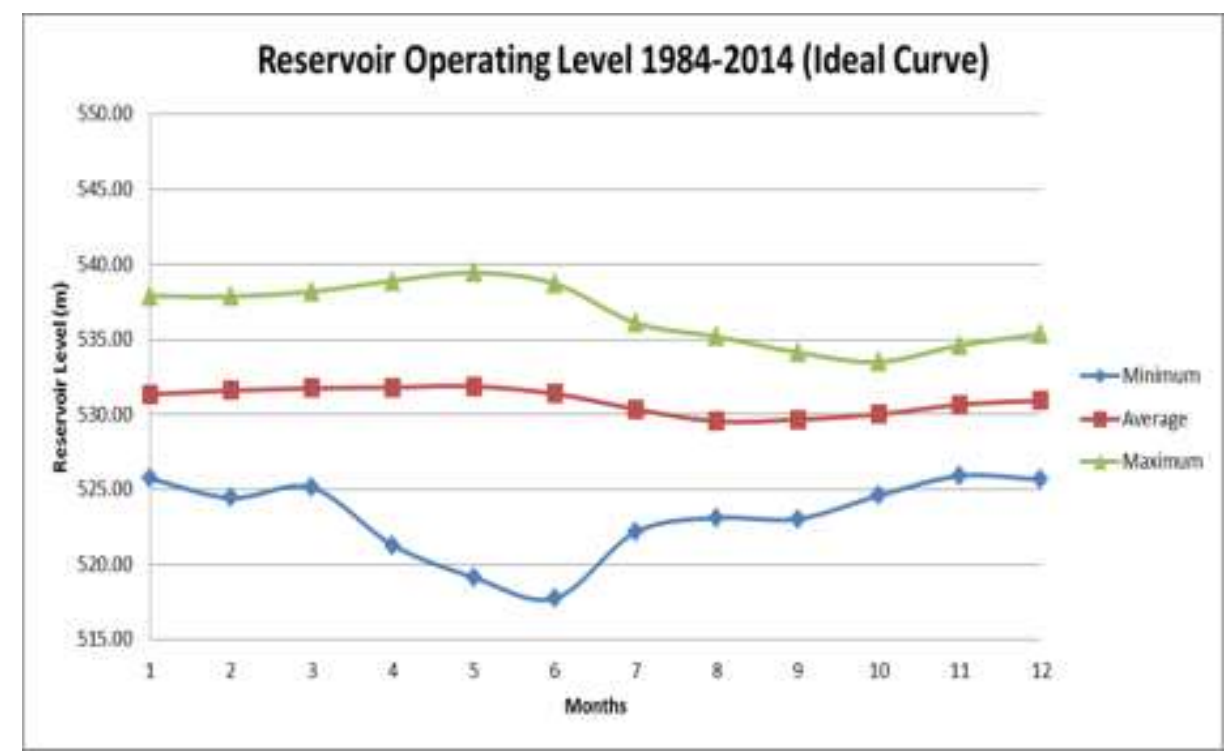

Figure 7: Ideal Rule Curve

\section{Proposed Regulated Rule Curve for Murum HEP}

For this model, the turbine discharges are also adopted as the parameters in this model following the similar path as SEB's rule curve and ideal curve. Real time operation for this dam reservoir dictates that it is not necessary the ideal rule curve can be applied for this dam. Hence, a more realistic rule curve is proposed. For this proposal, the regulated total outflows throughout the period from 1984 to 2014 are computed as shown in Figure 8.

A simulation was done from 1984 to 2014 for the mean rule curve. The overall result for the proposed rule curve is shown in Figure 8. For this study, a single analysis is conducted with no drop in the reservoir water level below $515.0 \mathrm{~m}$ throughout the 31 -year analysis. From the analysis, the month of June 1998 recorded the lowest level at $515.36 \mathrm{~m}$ which is slightly above the minimum operating level of $515.0 \mathrm{~m}$. This curve produces firm generation of 586.22MW. The proposed operating rule curve is illustrated in Figure 9.

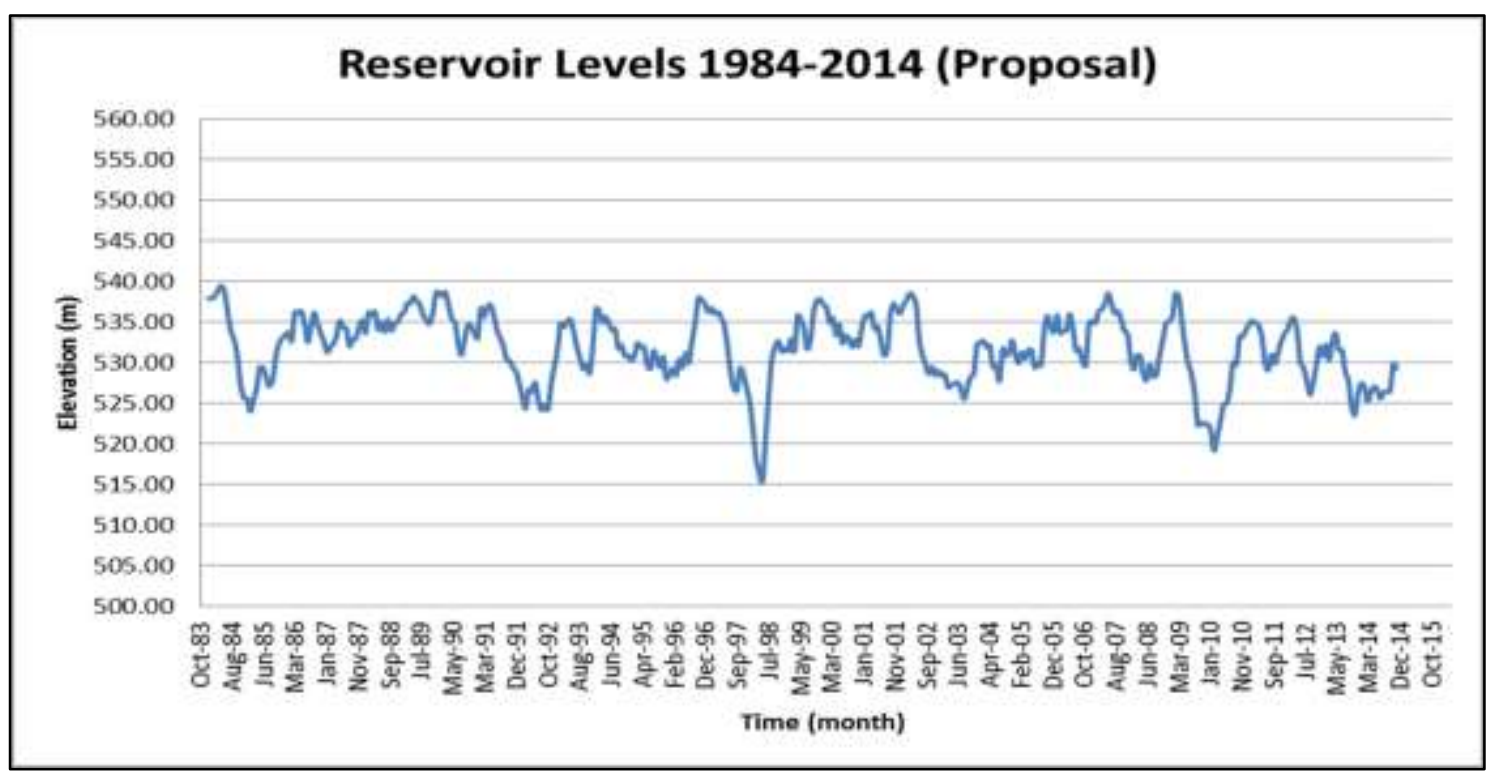

Figure 8: Murum HEP Overall Proposed Rule Curve 


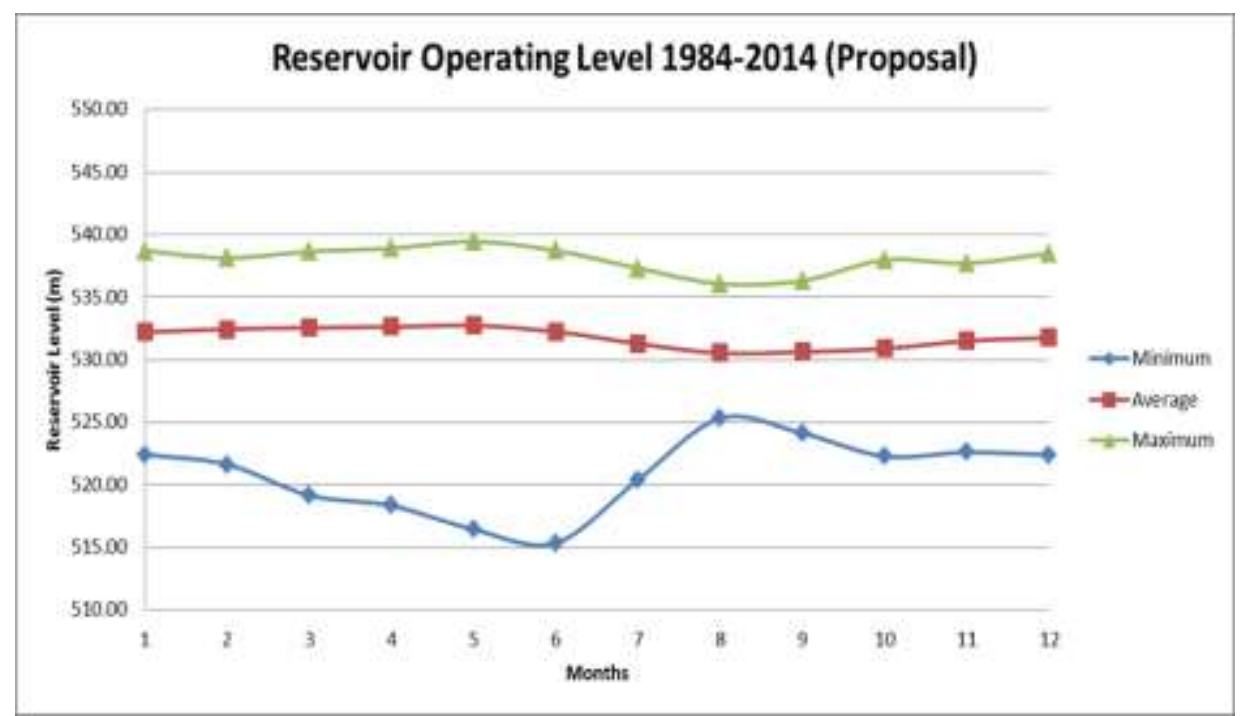

Figure 9: Proposed Rule Curve

It is justified to implement the n-1 operation, which is to operate three turbines for reservoir levels between $515.0 \mathrm{~m}$ and $540.0 \mathrm{~m}$ even if one turbine is down or under maintenance. Table 1 summarizes the minimum levels and firm generation capacities for all three (3) rule curves.

Table 1: Summary of Reservoir Level \& Firm Generation

\begin{tabular}{|c|l|c|c|}
\hline Item & \multicolumn{1}{|c|}{ Description } & $\begin{array}{c}\text { Minimum Level } \\
(\mathrm{m})\end{array}$ & $\begin{array}{c}\text { Firm Generation at 95\% } \\
\text { Exceedance }\end{array}$ \\
\hline 1 & $\begin{array}{l}\text { Regulated Rule Curve } \\
\text { (SEB) }\end{array}$ & 513.20 & 637.46 \\
\hline 2 & Ideal Rule Curve & 517.75 & 588.41 \\
\hline 3 & Proposed Rule Curve & 515.36 & 586.22 \\
\hline
\end{tabular}

\subsection{CONCLUSION AND RECOMMENDATION}

After reviewing various methods developing the operation rule curve, the most suitable method selected is the trial and error method. Stream flow sequential routing method is adopted for the simulation and creation of the operation rule model in this study. Aquarius Forecast is the hydraulic and hydrological software used to produce the rainfall runoff model for this study which is based on rainfall data from DID Sarawak. The monthly inflow series of the model are taken as the input into Microsoft Excel to simulate the development of the operation rule curves.

Based on the development and simulation of the operation rule from years 1984 to 2014, the ideal and proposed regulated rules are less than 635MW but with higher minimum levels than SEB's minimum level. This stems from careful and conservative idea, which is to ensure the reservoir levels are always remained within the range of $515.0 \mathrm{~m}$ to $540.0 \mathrm{~m}$, for both rules. Originally, the dam's design flow and firm generation are computed not only based on site measurements but also hydrological and hydraulic information of Bakun dam. These results, particularly the proposed rule curves, are still acceptable as the differences are not significant. This dam still has large storage and is able to fulfill the SCORE's requirement of energy 
supply. Furthermore, the environment and ecosystem of the downstream river are not neglected through the release of environmental flow at $8.0 \mathrm{~m}^{3} / \mathrm{sec}$.

It is worth to note that these results are merely a research exercise on the development of operation rule curve for Murum reservoir. This work represents the simulation based on new rainfall runoff relationship. Hence, the results are different than SEB's required generation. The total turbine discharges are one of the main parameters being applied for this study without considering the number of turbines. Therefore, this study is based on the assumptions; turbine discharge of $344.0 \mathrm{~m}^{3} / \mathrm{sec}$ for reservoir levels more than $540.0 \mathrm{~m}$ and $260.0 \mathrm{~m}^{3} / \mathrm{sec}$ for levels greater than $515.0 \mathrm{~m}$.

A more detailed study needs to be conducted to have more reliable procedures in the management of Murum reservoir operation. Firstly real records of river flow and water level; secondly more detailed site investigation on the topographical and geological aspects to improve the areal capacity curve. These aspects are important for the firm generation requirement by SEB. Lastly, it is also proposed to simulate the future research model based on number of turbines at each different discharge capacity instead of adopting overall total turbine discharges.

\section{REFERENCES}

[1] Verhaeghe, R.J. 1997. Reservoir Planning \& Operation, Systems analysis - simulation - evaluation,HH153/98/1, International Institute for Infrastructural, Hydraulic and Environmental Engineering, the Netherlands.

[2] Department of Irrigation and Drainage Sarawak, 2014. Resource Centre-IRBM 22 Basins. Available from: $<$ http://www.did.sarawak.gov.my/modules/web/pages.php?mod=webpage\&sub=page\&id=315\&menu_id=0\&sub_id=314>, Accessed on 9 Dec 2014.

[3] Drainage and Irrigation Department (DID). Sarawak Hydrological Yearbook 2012 Volume 39.

[4] Aquatics Informatics, 2015. Available from: <http://aquaticinformatics.com/products/aquarius-forecast/>, Accessed on $1 \mathrm{July} 2015$.

[5] Boyacioglu, S.E., 2013. Development of the Rule Curve for Altiparmak Hydroelectric Power Plant. .

[6] Boughton,W.,2003. The Australian Water Balance Model. Environmentally Modelling \& Software. Elsevier. 19(10), 943-956.

[7] U.S. Army Corps of Engineers, 1992. Hydrologic Engineering for Hydropower, Engineering and Design. Engineer Regulation No. 1110-2-1463. 